\title{
LA AUTOADAPTACIÓN: EL CASO DE MIGUEL DELIBES
}

\section{María Soledad GÓMEZ RUIZ}

Universidad Complutense de Madrid

\section{RESUMEN}

Este estudio está dedicado a tres novelas del escritor Miguel Delibes, cuya particularidad es haber sido adaptadas al teatro por el propio autor. El objetivo consiste en analizar comparativamente las adaptaciones teatrales de la trilogía de Delibes para demostrar la teatralidad implícita de los originales que justifica el éxito y las reposiciones de las correspondientes versiones. Por otra parte, es necesario reflejar el caso inusual de este escritor que reescribió sus novelas para la escena solo o junto a algunos colaboradores.

Palabras clave: Reescritura, autoadaptación, adaptación teatral de textos narrativos

\section{THE SELF-ADAPTATION: THE CASE OF MIGUEL DELIBES}

\begin{abstract}
This study focuses on three novels of the writer Miguel Delibes, whose particularity is being adapted for the stage by the author himself. The aim is to comparatively analyse the theatrical adaptations of the trilogy of Delibes to show the implicit theatricality of the original that justifies the success and reruns of the corresponding versions. Moreover, it is necessary to reflect the unusual case of this writer who rewrote his novels for the stage alone or with some partners.
\end{abstract}

Key words: rewriting, self-adaptation, stage adaptation of narrative. 
La autoadaptación: el caso de Miguel Delibes

\section{Introducción}

La reescritura es una actividad que se produce en toda traducción e interpretación escénica. Sin embargo, la operación que requiere una adaptación de novela o relato implica una transformación superior a la versión contemporánea de un texto dramático, salvo algunas excepciones. La transformación del texto narrativo implica una permutación de su naturaleza original: se aplican al texto base operaciones como la elipsis, sumario, adición, transformación y permutación. Este proceso afecta al original cuyo punto de vista varía; el texto dramático, sin embargo, potencia al personaje, sustituye el pasado por el presente y el discurso narrativo se transforma en diálogo (estos cambios principales, junto a los signos que intervienen en la representación, los ha de tener en cuenta el adaptador). La dramaturgia de textos narrativos plantea, por eso, muchas dificultades hasta convertir la obra en material dramático. La reescritura enfrenta al adaptador a dos exigencias: la primera tiene que ver con sus conocimientos sobre narratología y la segunda incide en el profundo saber escénico que requiere toda adaptación. Solo un especialista en la práctica teatral o un escritor que se implica en el proceso creativo del director y los actores podrá realizar una competente reescritura de textos narrativos. Este es el sentido de la dramaturgia actual que implica reescritura, traducción, adaptación, actualización e interpretación.

El estudio está dedicado a tres novelas del escritor Miguel Delibes, cuya particularidad es haber sido adaptadas al teatro por el propio autor y/o en colaboración con otros. El resultado de estas versiones teatrales es que además tienen la peculiaridad de haber sido editadas como obras teatrales; es el caso de Cinco horas con Mario, La hoja roja y Las guerras de nuestros antepasados. El objetivo del trabajo consiste en analizar comparativamente las adaptaciones teatrales de la trilogía de Delibes para demostrar la teatralidad implícita de los originales que justifica el éxito y las reposiciones de las correspondientes versiones. Por otra parte, es necesario reflejar el caso inusual de este escritor que reescribió sus novelas para la escena solo o junto a algunos colaboradores. Al parecer, todas sus novelas se caracterizan por estar protagonizadas por uno o dos personajes; así lo refleja, entre otros aspectos, el estudio introductorio de Gonzalo Sobejano (1981: 9-132) a la adaptación teatral de Cinco horas con Mario. Este autor es el primero que investiga la teatralidad del original de Delibes y lo compara con la versión escénica. Siguiendo sus pasos, planteo como hipótesis la teatralidad implícita de la trilogía de novelas del escritor basándome en la tensión dramática de Cinco horas con Mario, la trama progresiva de La hoja roja y el diálogo en Las guerras de nuestros antepasados como características principales de los textos referidos. El marco teórico se apoya en las teorías de los estructuralistas franceses y en Mijail Bajtín.

La reescritura es un fenómeno que puede afectar, en principio, a todo texto literario. La 
literatura circula por los canales culturales de la sociedad y es habitual que los elementos antiguos o tradicionales se mezclen con los nuevos y adquieran nuevas funciones. Esta circularidad reproduce los textos, los recrea y, por esta razón, se establece la vinculación entre textos y sujetos dentro de una dimensión comunicativa e interaccional que se denomina intertextualidad. La primera aportación al concepto tiene su origen en la estética filosófica de Bajtín (1979: 248-293): el autor afirma que todo enunciado es "una unidad real de la comunicación discursiva" y contiene una comprensión que provoca una respuesta (aunque el grado de participación sea variado). De aquí se desprende que todo texto literario es original y único en cuanto objeto estético, pero está configurado por toda clase de enunciados heterogéneos y tiene carácter "dialógico". El concepto ha sido elaborado, fundamentalmente, por Julia Kristeva (1997: 1-9) y aplicado a la semiótica a finales de los años 60. La autora define la literatura como una práctica social que aporta una cadena de "productividad". El discurso literario es un acto vivo en continuo diálogo, esto es, un "intertexto" que remite siempre a otros textos y cuya relación puede ser de contestación, refutación o, incluso, plagio. De ello se concluye que en todo texto literario coexisten elementos arcaicos y nuevos y que esta noción de intertextualidad se cumple en la reescritura. Por tanto, en la dramaturgia de textos narrativos, la versión o segundo texto se convierte en réplica o contestación del original que lo inspira. La nueva lectura proyecta textos del pasado y permite su recuperación, su transposición y, como contrapartida, su posible tergiversación. Sin embargo, Gérard Genette (1989: 10) es más restrictivo a la hora de definir el concepto. Establece la intertextualidad dentro de los cinco tipos de relaciones transtextuales y explica sus tres formas de manifestación: la cita, el plagio y la alusión. Finalmente se comprueba que en la adaptación de textos narrativos se cumplen dos tipos de relaciones de transtextualidad de acuerdo con Genette. Por una parte, la hipertextualidad afecta a toda adaptación teatral — pues requiere una transformación directa, pervertida o fidedigna del hipotexto- $y$, por otra, la intertextualidad se cumple objetivamente en las adaptaciones con incorporación, montaje o collage de textos externos. Esta copresencia de varios textos en el hipertexto puede ser del propio dramaturgo, de otras obras del escritor del hipotexto o de autores contemporáneos.

Merece ser destacado el caso de los autores que adaptan sus propios textos y los reescriben permutando el género literario. La autoadaptación provoca el encuentro de lo antiguo y lo nuevo; se trata de escritores con la facultad de expresarse en varios géneros literarios y artísticos. Sánchez Noriega (2000: 27) alude, en este sentido, a Fernando Fernán-Gómez porque, cuando el autor crea $E l$ viaje a ninguna parte, lo hace primero como guión radiofónico (1984) para adaptarlo después como novela (1985) y guión cinematográfico (1986). Por esta razón, en este trabajo se analiza el caso del escritor Miguel Delibes, el cual reescribe su conocida trilogía al teatro y demuestra con ello una gran 
complicidad con los lectores. Es un hecho que se puede constatar, por ejemplo, en las representaciones de Cinco horas con Mario: los espectadores tienen la posibilidad de comparar la relación interna entre los textos del propio autor, sus convergencias y divergencias. El tema de la adaptación al teatro tiene una larga tradición en la historia dramática; sin embargo, que sea el propio autor es un hecho menos usual. En España existe el precedente decimonónico de Benito Pérez Galdós, que adaptó siete de sus novelas al teatro. Pero que sea un hecho poco usual no significa que sea único en la narrativa contemporánea española. Por citar algunos ejemplos más de narrativa moderna de gran éxito, habría que aludir a dos novelas francesas en el XIX $-E l$ conde de Montecristo, de Dumas, y Los misterios de París, de Eúgene Sue- que fueron adaptadas al teatro por sus propios autores, debido quizá al éxito obtenido primero en sus ediciones como narraciones. Esta faceta muestra un tipo de reescritura, en la cual los mismos mundos ficticios - personajes, espacio, tiempo, conflictos, etc.- se recrean y transforman en dos o más géneros literarios. Silvia Barei (1991: 63) reseña esta relación entre textos del mismo escritor y lo ejemplifica con autores como Borges, Juan Carlos Onetti o García Márquez. Este tipo de reescritura se denomina intertextualidad limitada y acoge muy bien esta categoría especial de dramaturgias.

La estructura del artículo se apoya en el análisis comparativo de cada obra y sus respectivas versiones. La metodología para abordar cada texto es la misma en todos los casos: una introducción y análisis del original, la correspondiente versión y el análisis comparativo que establece las relaciones de hipertextualidad de ambos textos con sus variantes e invariantes. A continuación señalo las aportaciones e innovaciones de las versiones y el grado de fidelidad/creatividad de las mismas. También se contrastan los elementos del texto narrativo y dramático (acción, personajes, tiempo, espacio y discurso); de esta forma se pueden deducir pautas de adaptación según el tipo de relato, la extensión y la propuesta estético cultural.

Por último, conviene recordar que las novelas del autor también han sido llevadas al cine, que es quizá el medio más frecuente de adaptación de la narrativa desde el siglo XX. Sin embargo, a diferencia del teatro, en el caso de estas adaptaciones no interviene Delibes generalmente como guionista de su propia obra literaria. Han sido nueve las novelas llevadas al cine con gran éxito: El camino (1963), dirigida por Ana Mariscal, y la serie de TVE (1978), por Josefina Molina; Retrato de familia (1976), adaptación de la novela Mi idolatrado hijo Sisi, dirigida por Antonio Giménez-Rico; La guerra de papá (1977), adaptación de El príncipe destronado, dirigida por Antonio Mercero; Los santos inocentes (1984), dirigida por Mario Camus; El disputado voto del señor Cayo (1986), dirigida por Antonio Giménez-Rico; El tesoro (1990), dirigida por Antonio Mercero; La sombra del ciprés es alargada (1990), dirigida por Luis Alcoriza; Las ratas (1997), dirigida por Antonio 
180 Tropelías. Revista de Teoría de la Literatura y Literatura Comparada, 27 (2017) María Soledad Gómez Ruiz

Giménez-Rico y Una pareja perfecta (1998), dirigida por Francesc Betriú, adaptación de la novela Diario de un jubilado. 


\section{Cinco horas con Mario: la tensión dramática}

Cinco horas con Mario se publica en el año 1966 y es considerada una de las cien mejores novelas en lengua española del siglo XX. Miguel Delibes se define en su obra como un humanista preocupado por revitalizar y concienciar a los lectores de los valores humanos para lograr una sociedad más responsable y solidaria. Por esta razón, la crítica ha dado en decir que de todos sus personajes quizá sea Mario Díez Collado el alter ego más representativo del propio escritor. La novela comienza de una forma poco frecuente con la esquela que presenta al protagonista ya muerto en la primera página de la historia. Se deduce por el título que Mario es el protagonista de la historia, aunque es su desconsolada viuda, Carmen Sotillo, la que presenta y cuenta los hechos vividos con su marido. También la esquela sirve para presentar a los personajes de la ficción, es decir, a la familia que deja Mario Díez Collado y que los padres de Mario ya no viven ni tampoco la madre de Carmen Sotillo. Mario tiene una hermana, María del Rosario, una cuñada, doña Encarnación, viuda de su hermano Elviro y, por otra parte, Carmen Sotillo tiene una hermana, Julia.

La fecha de la muerte de Mario - el 24 de marzo de 1966, a los 49 años- constituye el marco temporal de la ficción de la novela. Termina la esquela con el anuncio de misa por el difunto al día siguiente (10 de la mañana del 25 de marzo de 1966). El lugar donde se desarrolla la obra no es mencionado pero sí se deduce, por la dirección de la casa y la parroquia, que podría ser cualquier ciudad de España. El arranque de la novela con una esquela es un procedimiento que invita a descubrir quién es el protagonista muerto y su historia. Tras la dedicatoria y la esquela, la novela contiene veintinueve páginas sin numeración ni título seguidas de veintisiete capítulos numerados en romanos y remata con catorce páginas sin título ni número capitular. La estructura de la novela consta de un prólogo y un epílogo en los que el narrador en tercera persona hace una descripción sumaria de las acciones y partes dialogadas entre varias personas — la principal la viuda — que sirven de marco de la novela. Los veintisiete capítulos en romanos comienzan con un párrafo en cursiva tomado de la Biblia. La viuda Carmen Sotillo mantiene este libro abierto sobre su regazo. La mayor parte del discurso de la novela es un monólogo en primera persona dirigido a un "tú", que es Mario Díez, el marido muerto.

Paso a analizar a continuación la adaptación teatral realizada por Miguel Delibes junto a sus colaboradores Santiago Paredes, José Sámano y Josefina Molina. La obra se estrenó en el Teatro Marquina de Madrid el 26 de noviembre de 1979 y, posteriormente, en Barcelona. La producción corresponde a José Sámano, los decorados a Manuel López, la escenografía a Rafael Palmero, los arreglos musicales a Carlos Montero, la música a Luis Eduardo Aute y las fotografías a Jordi Socias. El reparto de la primera época lo encabezaba Lola Herrera como Carmen Sotillo -personaje que 
interpretó durante veinte años con gran éxito de público y crítica- y su hijo Mario fue encarnado por Jorge de Juan. En la segunda época el reparto siguió siendo protagonizado por Lola Herrera con el cambio de Pablo Rodríguez en el papel del hijo. La tercera época de reposición de la obra tuvo lugar el 12 de marzo de 2010, tras la muerte de Miguel Delibes. El nuevo reparto estaba protagonizado por Natalia Millán como Carmen Sotillo y Víctor Elías como su hijo. La dirección escénica corrió a cargo de Josefina Molina desde la primera época hasta que volvió a dirigir la obra treinta y un años después, en septiembre del año 2010, con la interpretación de Natalia Millán y la producción de José Sámano en las tres épocas. La adaptación al teatro es realizada por Miguel Delibes, Josefina Molina, Santiago Paredes y José Sámano en la primera época. En la segunda y tercera época la adaptación corre a cargo de Miguel Delibes, Josefina Molina y José Sámano. Así la obra se representa por toda España en tres etapas, que resumo a continuación: la primera (1979, 1980, 1981, 1984 y 1989), la segunda (2001, 2002, 2003, 2004 y 2005) y, la tercera (2010, 2011 y 2012). Como último aspecto sobre las versiones de la novela conviene recordar que la directora Josefina Molina también se inspiró en Cinco horas con Mario en 1981 al rodar la película Función de noche, interpretada por Lola Herrera.

La comparación está basada en los dos textos literarios, la novela (2010) editada en Austral y el drama (1981) publicado por la editorial Espasa Calpe, con el estudio introductorio de Gonzalo Sobejano (1981: 9-132). Estoy de acuerdo con este autor en que el drama conserva la calidad literaria de la novela; lo que se pierde es debido a la reducción y la síntesis necesarias para que la obra sea representable: cincuenta y seis páginas para la versión teatral respecto a las doscientas treinta y cinco de la novela. En cambio, gana al ofrecer una lectura ya hecha, que es el espectáculo con la interpretación actoral y toda la semiótica de la representación.

Los temas y motivos que se suceden desde el comienzo de la representación son la esquela, los comentarios sobre la muerte de Mario, el aspecto del cadáver, los juicios sobre su calidad humana, las opiniones de sus amigos y de los humildes, el extremado dolor de su cuñada, la razón de la muerte de Mario -un infarto- y la llegada de un telegrama. La acotación indica que entre todo esto debe de haber "bullicio y cotilleos". Por último, cuando Carmen se despide de Valentina e indica a su hijo que se acueste, la segunda acotación precisa que comienza a oírse un tema musical que es de un solo instrumento, el corno inglés. El argumento de Cinco horas con Mario coincide en ambos textos; sin embargo, me ha resultado muy difícil sintetizar las asociaciones espontáneas del personaje y los temas y motivos que aparecen en cada capítulo de la novela y la versión, puesto que la conciencia de Carmen se desplaza constantemente y se detiene en los temas del pasado, los recuerdos y su presente más reciente. El monólogo no es progresivo, ya que Delibes alterna los temas obsesivos 
de Carmen y repite los que más le afectan con un enfoque retrospectivo, de manera que el lector va deduciendo la incomunicación del matrimonio y el sentido de culpa de la protagonista hasta su confesión, por el desliz con Paco, en el capítulo XXVII. En cambio, la acción dramática avanza por el clímax emocional que alcanza la viuda que parece reclamar la respuesta y el perdón del difunto antes de su entierro. En la versión se recurre de forma más amplia a los capítulos VI, XV, XIX, XXIV y XXVII. Los recuerdos de la guerra civil se reproducen en el monólogo y de forma casi literal la anécdota de la muerte de los padres de Mario del capítulo VII. El espacio y el tiempo de la ficción tienen una teatralidad implícita puesto que todo ocurre en la casa del matrimonio la noche anterior a su entierro. El tiempo está condensado en la novela y transcurre en las pocas horas del velatorio, lo que hace que sea dramatizable. El monólogo teatral desarrolla la acción en el despacho de Mario donde se encuentra el féretro. Todas las voces del prólogo se muestran en off en la versión para indicar el tiempo anterior hasta que Carmen se despide de Valen y su hijo. Las acotaciones son muy importantes porque describen la escenografía, la iluminación que atañe a los momentos más o menos intimistas de Carmen y las acciones del personaje que coinciden con las didascalias. El tiempo muestra la progresión cronológica cuando se indica mediante la acotación que el reloj avisa a Carmen de que son las cinco y pronto la sorprende su hijo Mario en la escena final; la iluminación del escenario rompe la intensidad emocional de Carmen y anuncia el amanecer.

La primera diferencia del monólogo respecto a la novela consiste en la supresión de todos los pasajes bíblicos que marcaban el inicio de cada uno de los veintisiete capítulos. En cambio, la Biblia está en todo momento en escena entre las manos de Carmen, en la mesa, etc., aunque la protagonista no lee ningún versículo en el drama. Se suprime en la versión la intertextualidad entre los versículos del texto sagrado, y el monólogo queda reducido a un signo que refleja la religiosidad de Carmen Sotillo. Los temas de la novela se mantienen en la versión teatral: el sexo, el dinero y la autoridad. También permanecen invariantes la ideología, el marco social e histórico y el simbolismo de la novela. La versión suprime personajes de la novela como Esther, la intelectual admiradora de Mario, y su esposo Armando, el francés Perret y el padre Fando, contertulios de Mario. No se menciona la presunta anormalidad de Álvaro, la tendencia intelectual de Borja, Charo, los poetas Canido y Borrés ni la parva estatura de Aran. También se suprime al barrendero a quien saluda una vez Mario por la calle, los locos que tanto le preocupan y el portero con quien habla su hijo. Estos personajes no añaden al espectador información necesaria ni tienen entidad suficiente para el conflicto dramático.

La composición verbal del hipertexto se ha reducido mucho para hacer representable el monólogo. No varia el ritmo reiterativo que caracteriza el pensamiento obsesivo de Carmen Sotillo y se mantienen los motivos ideales de la novela como el elogio a la bravura o el contraataque de 
Carmen a lo que su marido llamaba "servilismo". Pero todos los capítulos de la novela están representados en el hipertexto aunque solo sea un párrafo para cada uno. Gonzalo Sobejano enumera (1981: 109-113) los capítulos más aprovechados y en la versión: I (los principios de Carmen, amor y celos), II (parquedad de Mario, dinero, utilidad e inutilidad), VI (caridad), VII (guerra civil), XV (autoridad), XIX (soledad de Mario en sus ideales caritativos), XXIV (enfermedad de Mario) y XXVII (la confesión Carmen).

La novela no tiene acotaciones, no sabemos cómo gesticula o se mueve Carmen Sotillo ni su aspecto físico o la decoración de su casa. En la novela el monólogo ocurre en la conciencia de Carmen mientras la versión teatral ubica temporal y espacialmente en escena al personaje en una realidad ficticia pero perceptible para el espectador. El lector del monólogo dramático se hace idea de lo que no ve o percibe por las acotaciones; éstas se desarrollan simultáneamente a las palabras de Carmen Sotillo y su interpretación, revelan pausas, cambios de estado de ánimo, de luz o espacio, etc. El atrezzo personal — la Biblia, el rosario, las gafas, toquilla, rebeca, pañuelo, los zapatos y las horquillas - añaden información de cómo es esa mujer. El termo en la mesa es un signo de las cinco horas que pasa Carmen junto al marido muerto.

El epílogo en la adaptación también sufre cambios y reducción. Se condensa la escena del diálogo entre Carmen y su hijo Mario y se suprimen las visitas que llegan para acompañar a la viuda en la misa. Aunque la escena queda muy bien condensada, la variante es que el diálogo lo mantienen en el mismo despacho ante el cadáver del padre y, en cambio, en la novela el hijo lleva a su madre a la cocina donde mantienen la conversación. El cambio más destacable del epílogo en la versión teatral es que se suprime el mensaje antimaniqueísta del hijo. En la novela es muy interesante la exaltación de Mario pero, según Gonzalo Sobejano, en el teatro sonaría a tesis y a propaganda ideológica de izquierdas; considero también que es un acierto suprimirlo (2010: 319-321): “¡Por Dios, mamá! Ya salió nuestro feroz maniqueísmo: buenos y malos [...] ¡los buenos a la derecha y los malos a la izquierda! Eso os enseñaron ¿verdad que sí?”. Delibes, por el contrario, lo sustituye en la obra dramática (1981:191): "Mario.- (Azorado) Por favor mamá. (Toma una petaca de la mesa y se la muestra). ¿Te importa que me quede con su petaca? Carmen. -¿Pero a ti te gusta ese tabaco, hijo? (Mario asiente sin contestar)". Cambia el carácter directo y el plano ideológico de la novela por un diálogo que en la versión teatral deja ver claramente que el hijo piensa y es como su padre. Lo didáctico en la novela es matizado y se convierte en algo sugerido y reemplazado por el detalle de la petaca que desea heredar el hijo. Pero el mensaje de ambos textos es el mismo y eso lo mantienen Delibes y sus colaboradores: que el hijo es como su padre y piensa luchar por los mismos ideales. El detalle de que Mario sufre los mismos síntomas que el padre queda patente en el final de la versión 
(1981: 191). Al bajar el telón, la acotación indica que se escucha de nuevo la música del principio. La versión enfatiza lo dramático que ya es evidente en la novela. 


\section{La hoja roja: una trama progresiva}

El proceso de escritura de La hoja roja estuvo arropado por una beca de la Fundación March, ayuda que permitió a Delibes dedicarse a la creación de una novela en un plazo de tiempo razonable. La obra fue publicada en 1959 y se tradujo en Francia, Rusia, etc.

La historia del jubilado en precario don Eloy y su criada analfabeta Desi describe la confluencia de dos soledades fuera de las barreras de la edad, clase social u otro tipo de convenciones, centrándose en el amparo que un ser puede dar a otro para aliviar su soledad y sufrimiento al margen de las convenciones sociales. El propio Delibes tuvo conciencia muy pronto de que era una historia fácilmente adaptable al teatro por sus limitaciones espacio-temporales. La acción dramática de sus dos protagonistas plantea conflictos en paralelo que evolucionan hacia un clímax y un desenlace que los une.

En el prólogo de la versión teatral (1987: 10-13), Delibes cuenta su primer intento de adaptación teatral en la época más brillante del realismo-social junto a José María de Quinto, autor de relatos especializado para la escena. Aunque no llegaron a terminar ni el borrador de la obra, sí discutieron las posibilidades escénicas y la posible estructura dramática. Después, a finales de los años 60, vino la colección de RTV, cuya intención era divulgar un centenar de obras literarias al módico precio de 25 pesetas; La hoja roja hacía el número 17 de la colección y se vendió de manera sorprendente. La trayectoria de esta novela prosiguió con el intento de varios directores de cine que solicitaron los derechos para hacer una película. El propio autor afirma que se negó porque su intención personal era llevarla al teatro; hizo una versión teatral un tanto simple (según relata el propio Delibes) por falta de presupuesto en la producción, pocos personajes y un solo decorado. Una vez terminada la adaptación, el autor hizo algunas gestiones para estrenarla, pero se presentó el productor Juanjo Seoane quien, después de leer la versión, sugirió junto al director escénico Manolo Collado, enriquecerla convirtiendo la obra en una función con siete decorados, quince cuadros y hasta siete figurantes. En la producción del espectáculo de Seoane colaboró el Ayuntamiento, el Ministerio de Cultura y la Diputación de Valladolid.

Esta es la historia de La hoja roja en su versión teatral: se estrenó el 6 de septiembre de 1986 en el Teatro Calderón de Valladolid dirigida por Manolo Collado, adaptada por el propio Delibes y producida por Juanjo Seoane. Tras su estreno, se representó en Madrid el 21 de septiembre en el Teatro Alcázar. El reparto estaba encabezado por Narciso Ibáñez Menta en el papel de don Eloy y María Fernanda D’Ocón en el de la Desi; finalmente, la versión teatral se publicó en 1987 en la editorial Destino. Según Pere Gimferrer en el prólogo que precede a la versión teatral (1987: 19-20), el mayor mérito de La hoja roja es su versión escénica, además del logro de crear dos personajes 
redondos ya en la novela, que no necesitaban revisión ni nuevo tratamiento en la adaptación.

Sigue el análisis comparativo de la novela (2010) junto a la versión teatral (1987), puesto que los cambios que se dan son connaturales en el paso de un género a otro. El texto narrativo consta de veintidós capítulos, encabezados con números romanos, en los que se desarrolla la historia en doscientas treinta y nueve páginas. La trama relata la historia de don Eloy a partir del momento en que se jubila tras cincuenta y tres años como funcionario municipal. El Alcalde ofrece una cena en su honor y le entrega una medalla de plata. Comienza el hipotexto con un narrador omnisciente que presenta a don Eloy y los tres momentos importantes de su vida: la boda con Lucita, su esposa, su afición e intervención en la Sociedad Fotográfica y la noche que estaba a punto de llegar de celebración de su jubilación.

El título de la novela conecta con la frase que dice su amigo Pepín Vázquez (2010: 21): “a mí me ha salido la hoja roja en el librillo de papel de fumar”. Delibes explica en nota a pie de página que en los librillos de papel de fumar suelen incluir en España una hoja, en la que se advierte al usuario: "quedan cinco hojas". Esta explicación, junto a la frase del mismo Vázquez tres años antes de morir "la jubilación es la antesala de la muerte" presentan el conflicto del protagonista don Eloy, es decir, el miedo a la muerte y su soledad a partir de jubilarse. El incidente desencadenante de ese miedo es la muerte de su gran amigo Isaías (por una gripe), al que le unía una gran amistad desde la infancia. La trama de la novela plantea una estructura dramática perfecta que evoluciona de forma lineal y ascendente con un planteamiento inicial de las vidas de don Eloy y su criada, protagonistas de la historia, y sus dos conflictos, que se destapan totalmente tras la muerte de Isaías. El primero es el viaje a Madrid del viejo jubilado, donde se va a acrecentar su angustiosa soledad, y el segundo es el enfrentamiento de Desi a "la veta mala" de Picaza, que arruina la vida de ambos y sus ilusiones con el asesinato y consecuente condena de éste último. La historia desemboca en un auténtico acontecimiento patético que se ajusta a las claves del realismo social de la generación teatral de Delibes. La pareja de don Eloy y Desi se conforma al comprender ambos su soledad y el miedo que les condiciona a no encontrar otra salida mejor que vivir juntos y compartir lo poco que tiene el viejo. Por ello, la historia y los dos personajes principales cumplen los requisitos de un auténtico texto teatral cuya acción dramática queda muy bien definida ya en la novela. Estas dos características justifican la adaptación y el cambio de género literario que, a mi parecer, en este caso específico, es la versión teatral la que culmina y hace aún más brillante la historia.

A continuación analizaré las variantes de la versión teatral de La hoja roja respecto al hipotexto de Delibes. La novela desarrolla la historia en doscientas treinta y nueve páginas, pero el autor comprime la trama al trasladarla al código teatral y reduce la historia a noventa páginas, sin que 
pierda ninguno de sus motivos. El cambio de código supone tres modificaciones importantes: la supresión del narrador omnisciente para crear un discurso directo en la obra dramática, el comienzo de la versión teatral in medias res con el discurso de la jubilación de don Eloy y, por último, la supresión de los pasajes sobre la afición a la fotografía que dilatarían la pieza con el peligro de distraer al espectador del nudo dramático. La estructura dramática de la versión consta de dos actos donde se condensa perfectamente, con el principio in media res, el planteamiento, nudo y desenlace que lleva a la transformación de los protagonistas. Se vale en toda la obra de los diálogos de los personajes (frente al discurso narrativo de la novela). Las descripciones de la novela son sustituidas por el diálogo y las acotaciones de la pieza teatral. Delibes crea una obra dramática compleja que consta de dos actos estructurados en quince escenas o cuadros.

Las acotaciones son otro de los grandes aciertos; en el hipertexto se describen y detallan todos los signos verbales y no verbales necesarios para la representación: sirven de marco para ubicar el espacio y tiempo de la ficción y su evolución en cada escena. Describen la representación virtual con los siete decorados y remiten al espacio y el tiempo de la representación a través de la escenografía, los decorados, la luz y el sonido.

Los personajes de la versión teatral y de la novela giran en torno a dos órbitas, la de don Eloy y la de Desi. El desenlace final une a ambos personajes por su soledad; no hay por qué llamarlo amor, pero sí es preciso admitir que Eloy y Desi son dos seres que se reconocen uno en el otro. La versión teatral respeta a casi todos los personajes de la novela, salvo algunas variantes que se verán ahora; los personajes protagonistas son don Eloy y Desi. Los secundarios con importancia en la acción dramática son Picaza, Isaías y Marce. Los personajes con menor intervención o texto en la versión teatral son el cabo Argimiro, León, Suceso, Áurea y Lupe. Y, por último, el fotógrafo (aparece dos veces: la primera solo sugerido en la primera acotación) y el guardia. Se suprime de la novela a don Pacheco y, por tanto, la visita de don Eloy a la óptica (2010: 111-117) para estimularle a reorganizar la Sociedad Fotográfica y también su visita a la Corporación y la reacción de sus antiguos compañeros (2010: 109-111) como Carrasco, don Cástor o Mauro Gil. También se omiten de la cena de su jubilación los personajes que acompañan a don Eloy (2010: 13-19): Mauro Gil, su compañero de Negociado, que le espera para ir con él al restaurante, el Alcalde, don Cástor, Carrasco, Pérez Ballester y Martinito. Solo se reproduce en la versión teatral el discurso de don Eloy y los flashes de un fotógrafo sugeridos en la primera acotación, que también aparece en la novela. Tras la despedida en el restaurante se suprime también el paseo de vuelta a casa de don Eloy acompañado por Mauro Gil y la conversación que mantienen ambos (2010: 19-22). También se omite en la novela al camarero Pepito, que sirve en casa de su hijo León, y el gato Fausto, que mira y 
asusta a don Eloy (2010: 221-223). Como variante más notable, a la que ya he aludido, hay que mencionar el comienzo en la versión in media res con el discurso de don Eloy. En la novela, un narrador omnisciente presenta a don Eloy en la noche importante para la que se prepara, además de los tres momentos relevantes de su vida y su afición por la fotografía (2010: 9-13). Después describe cómo sale vestido para la cena y la conversación que mantiene con Desi. Se suprimen descripciones, aunque muchas serán llevadas a los diálogos de los personajes, de donde el espectador obtiene la información necesaria respecto de la vida pasada de los protagonistas, como por ejemplo, los pensamientos de don Eloy hacia su mujer Lucita o sobre su tío Hermene, y la Antonia y Goyito, su hijo muerto. Por otra parte, habla Desi de su medio hermano Marcos, muerto en una riada, el Raposo, la Caya, su madrastra, las fiestas de su pueblo y la celebración de las bodas, etc. Todos estos personajes de las vidas de ambos aparecen en los diálogos que mantienen los personajes en la representación. Se trata de una adaptación como transposición: los pasajes y personajes omitidos en la versión sirven para condensar la acción dramática de ambos protagonistas y sus dos mundos quedan perfectamente definidos con el conflicto y el desenlace que respeta plenamente el espíritu de la novela en la versión teatral de Delibes.

Se ha podido constatar que el tiempo de la novela evoluciona linealmente: los hechos se desarrollan desde noviembre hasta la llegada de la primavera. La versión condensa el tiempo de la acción desde la llegada del invierno hasta la segunda quincena de febrero y se especifican en las acotaciones ciertos momentos: la nevada de mediados de noviembre, el cumpleaños de Desi en diciembre, Nochebuena y la llegada de Picaza, tras los Reyes. Las acotaciones también indican mediante la luz si es por la mañana, tarde o noche. La acción dramática omite temas secundarios de la novela: Pacheco y la óptica en los capítulos X y XV, el camino hacia el restaurante y la vuelta a casa con Mauro Gil del capítulo I, el paseo de Eloy por el cementerio y su vuelta en coche fúnebre del capítulo XVIII. Por otra parte, varían algunos motivos del hipotexto: en la escena 7 Desi no recibe carta de su hermana con el aviso de que Picaza llegará después de Reyes sino que se lo dice directamente a don Eloy y lo celebran. Se suprime también la conversación del capítulo XVII entre Mamés, Eloy, Lupe y Áurea tras cobrarles siete duros por afeitar al muerto. La versión muestra, en cambio, la llamada que hace Áurea al barbero. El discurso de la novela alterna las intervenciones del narrador omnisciente, las descripciones y narración del pasado de los personajes junto a las conversaciones en estilo indirecto. Se mantiene el realismo del lenguaje de Delibes, las acotaciones sustituyen al narrador y precisan el tiempo, ambiente, lugar y acciones de cada escena. Por último, el diálogo tiene una función dinámica al reducir al máximo las réplicas de los personajes para agilizar el ritmo escénico. 
190 | Tropelías. Revista de Teoría de la Literatura y Literatura Comparada, 27 (2017)

María Soledad Gómez Ruiz

\section{Las guerras de nuestros antepasados: del diálogo al diálogo}

Esta novela tuvo su primera edición en 1975. La historia se centra en Pacífico Pérez; como afirma el propio autor en el prólogo de la versión (1990: 9); los personajes de sus relatos “están presionados por el entorno social, suelen ser perdedores, víctimas en una u otra medida de la ignorancia, la miseria, el miedo, la organización o la violencia”. El discurso realista refleja la psicología y el contexto social del presidiario. La conversación que mantiene con el doctor Burgueño dura siete noches con alguna copita de anís por medio. El recluso, a partir de las preguntas del médico del sanatorio penitenciario donde está internado, irá recordando momentos importantes de su vida. Según Miguel Delibes (1990: 10), esto demuestra que Pacífico era "un muchacho hipersensible que por mor de la violencia circundante -no sólo la de sus belicosos familiares- acaba convirtiéndose gratuitamente agresivo, inhibido y escéptico”. El diálogo mantenido entre el recluso y el doctor refleja la presión que puede condicionar a un ser humano en sus actos, la represión de su libertad natural y la responsabilidad de los hechos. El doctor graba en su magnetófono durante siete noches las conversaciones e indaga en los hechos que llevaron a Pacífico al asesinato del Teotista, hermano de su novia Cándida, por lo que fue condenado a veinte años de prisión. También su participación en la fuga de la cárcel por la que se le acusa de un nuevo crimen: el doctor quiere probar su inocencia respecto de este último cargo, ya que está pendiente el juicio; también muestra su simpatía por el preso, que es ingresado en el sanatorio penitenciario a causa de una grave dolencia pulmonar (una fibrosis bilateral).

La novela (1975) está estructurada en tres partes: la primera se dedica a la exposición del narrador, el doctor Burgueño, que presenta la historia de su paciente Pacífico Pérez, la fecha en que ingresó en el Sanatorio de Navafría (25 de marzo de 1961) y la piedad que sintió por él al descubrir su propensión a un fallo cardiorrespiratorio. Continúa con una descripción del carácter y comportamiento en la cárcel del protagonista y de sus rasgos físicos. El doctor cuenta que lo que llamó su atención fue que, a las dos semanas de entrar en el sanatorio, Pacífico comenzó a construir un pequeño jardín en el ángulo noroeste del patio y recibió una única visita: la de una muchacha y su hijo de pocos meses. Esto, su carácter inhibido y sus gafas, entre otras consideraciones, no le imprimían una personalidad de hombre rural. A partir de estos indicios, el doctor llega a obsesionarse con el deseo de ayudar a Pacífico Pérez, como afirma ante el lector; cita en su despacho al recluso al final del día para favorecer la intimidad y poder conocer los hechos de su desgracia. Las charlas entre ambos se desarrollan entre el 21 y el 27 del mes de mayo del año 1961 y se disponen en siete noches -cada una un capítulo. Toda esta parte del diálogo de la novela tiene una teatralidad implícita que lo hace representable escénicamente. Los temas sobre los que indaga este son: el amor 
de Pacífico por la naturaleza, su familia, su novia, la muerte del Teotista, la construcción del túnel y la fuga en la que participó y por la que se le acusa de otro crimen.

Por último, la novela cuenta cómo fue el final del protagonista Pacífico Pérez: muere en el Sanatorio Penitenciario, donde estaba recluido con una pena de treinta años por clemencia del Jefe de Estado. Su deseo antes de morir fue contraer matrimonio con la señorita Cándida Morcillo para darle padre a su hijo, cosa que irritó a su padre Felicísimo, pues la consideraba una mujer ligera de cascos. Al poco murió confesándose y recibiendo la comunión.

La versión teatral de Las guerras de nuestros antepasados tiene su primera edición en 1990. La obra fue adaptada a escena por el propio autor junto a Ramón García y dirigida por Antonio Giménez-Rico. La versión fue estrenada el 7 de septiembre 1989 en el teatro Bellas Artes de Madrid, publicándose en octubre de 1990 por Destino ediciones. El reparto estaba formado por José Sacristán, que encarnaba a Pacífico Pérez, y Juan José Otegui, al Dr. Burgueño; la escenografía fue realizada por Rafael Palmero y la producción corrió a cargo de José Sámano. Las representaciones de Las guerras de nuestros antepasados se distribuyen a lo largo de tres épocas: la primera, ya citada, dirigida por Antonio Giménez-Rico e interpretada por José Sacristán y Juan José Otegui, corresponde a los años 1989, 1990 y 1991. La segunda época coincide con 1992, dirigida por José Sacristán, y el reparto varía: Manuel Galiana interpreta a Pacífico Pérez y Juan Jesús Valverde al Dr. Burgueño. La tercera etapa abarca desde el año 2002 hasta el 2005, dirigida por José Sámano e interpretada por Manuel Galiana como Pacífico Pérez y Teófilo Calle/ Juan Jesús Valverde como Dr. Burgueño. En 1991 se representa en Buenos Aires y en 1994 en París con el título La guerre promise.

Los adaptadores de la versión, Delibes y Ramón García, plantean la acción dramática en un solo acto. Hay una primera acotación que describe cómo ha de estar dispuesto el escenario y la escenografía. La acción se desarrolla en toda la obra en un solo lugar: el despacho-consulta del Dr. Burgueño López en el sanatorio penitenciario de Navafría. Las indicaciones son sencillas respecto al mobiliario que ha de tener el despacho de una consulta médica: una mesa, armario o alacena con material médico, tubos de ensayo y objetos de laboratorio, fichero para historiales, una cama ortopédica, alguna silla suelta. El elemento principal de la escenografía indica que habrá una gran ventana con barrotes en la pared del fondo, a través de la cual la luz marcará el paso del día a la noche, poco a poco. El resto de acotaciones en todo el acto indican los movimientos de los actores por el espacio y sus acciones así como los cambios de luz y los oscuros. La versión teatral es bastante fiel al hipotexto, salvo algunas variantes y supresiones. En primer lugar, la adaptación mantiene la misma estructura de la novela en cuanto a la división de los hechos en tres partes: en la novela el Dr. 
Burgueño presenta al protagonista Pacífico Pérez y describe a los lectores cómo es su paciente físicamente, su enfermedad y por qué está en la cárcel. La versión teatral traduce fielmente esta primera parte y coloca al Dr. Burgueño (Juan José Otegui) en el proscenio para dirigirse al público y lo ilumina solo a él, dejando el resto del escenario a oscuras. Así los dramaturgos justifican la presentación de Pacífico Pérez, el paciente ingresado con una grave dolencia pulmonar, una fibrosis bilateral. El doctor confiesa al público su obsesión por ayudarle ya que ha sido condenado de nuevo por otro asesinato y esta condena como reincidente podría ser capital. Además, presenta a los espectadores el proceso de sus encuentros y cómo al principio Pacífico se limitaba a asentir hasta abrirse y poder grabar las charlas en su magnetófono. El público va a ser testigo de una charla grabada una tarde de primavera de 1961.

La segunda parte comienza con una acotación que indica el cambio de luz en todo el escenario y la acción del doctor acercándose a su mesa de trabajo y pulsando la tecla del magnetófono. Otra acotación indica las acciones que realiza el doctor mientras prepara la llegada de su paciente: extrae unos sobres con semillas y su expediente del fichero, prepara el magnetófono hasta escuchar cómo llaman a la puerta y se dirige a abrir. Toda la segunda parte mantiene el mismo tipo de discurso: el diálogo entre ambos personajes es la única modalidad en la novela y ha sido adaptado para la versión con notables supresiones. Se mantiene en la versión teatral la misma evolución de los hechos y temas tratados en las conversaciones entre ambos personajes, pero el tiempo no se dosifica como en la novela en siete noches y sus respectivos capítulos. En la versión teatral el desarrollo de la acción se concentra a una sola conversación grabada, como anticipa el Dr. Burgueño, en una tarde de primavera de 1961. Después la acotación indica cuándo sale Pacífico Pérez de la consulta y el doctor pulsa la tecla stop del magnetófono.

La tercera y última parte de la adaptación comienza cuando el doctor Burgueño se acerca a proscenio y queda solo, iluminado como al principio, y se dirige al público. La variante más notable en esta tercera parte de la versión teatral es que los dramaturgos acentúan la injusticia ejercida contra su paciente, Pacífico Pérez, en dos aspectos: en primer lugar, el doctor Burgueño cuenta al espectador que, al celebrarse el juicio quince días después, acuciado por su conciencia y con el permiso del tío de Pacífico, don Francisco Pérez, puso las cintas grabadas en manos del juez y cómo la prueba fue desestimada y su paciente condenado a muerte. En segundo lugar, tras la petición del recluso de contraer matrimonio con la señorita Cándida Morcillo (esta es una invariante común al hipotexto), Pacífico Pérez fue condenado a muerte y ejecutado a garrote la madrugada del día 13 de septiembre de 1961. El destino final de Pacífico Pérez es más suave y compasivo en la novela de Delibes: el condenado muere el mismo día, el 13 de septiembre, pero en diferente año respecto a la 
versión teatral (1969). Los hechos también varían en el hipotexto porque el autor, a través del doctor, narra cómo fue ingresado por sufrir tres hemoptisis con breves intermitencias el 11 de septiembre en el Sanatorio Penitenciario de Navafría, donde cumplía condena. Y el hecho invariante respecto a la versión teatral es que fue condenado a muerte a garrote por el Tribunal. En la novela, en cambio, la pena le es conmutada por treinta años de reclusión por clemencia del Jefe de Estado.

Los personajes de Delibes viven acuciados por alcanzar una vida auténtica y, quizá por ello, en la versión teatral quieren acentuar más el mensaje latente en la novela. Delibes junto a Ramón García adaptan el hipotexto, como se ha dicho, condensando la acción dramática en los cuatro temas que interesan al doctor para intentar salvar al acusado. Los adaptadores concentran la trama en 55 páginas en la versión, mientras la novela puede demorarse en relato de los hechos de la segunda parte, donde ambos conversan a lo largo de 280 páginas.

Para concluir, es preciso aludir a las supresiones en la versión teatral. No se mencionan los trances de su abuela Benetilde en la novela (1975:18-19) ni el amor que sentía por ella (1975: 65-68) y su aureola de santa (con sus éxtasis). Los sábados esta recibía a gente que venía de lejos y Pacífico cuenta cómo su fama atraía a muchos forasteros al Human para consultarle. También se omite cómo los del pueblo del Otero la querían matar por no tolerar las colas que se formaban de gente. El suicidio de su abuela (1975: 94-102) queda suprimido en la versión e incluso la descripción de la muerte de su madre (solo es nombrada en la versión) (1990: 37). Tampoco se cuenta el día que muere el jabalí (1975: 64), es decir, cuando todo el pueblo del Human vio caer y golpearse contra el cemento de la plaza a este animal; que queda reventado. Otra supresión es la mención de Corina, su hermana que, al morir su madre, se enfrenta al patriarcado (1975: 107-108). De su padre se omite, al contarle al doctor los aspectos belicosos de su Bisa y del Abue, su ocupación en los negocios de tractores y cosechadoras (1975: 53) y el fragmento en que cuenta cuando le reventó un obús entre las piernas y la cantidad de metralla que entró en su pierna derecha (1975: 55) hasta que se le curó la herida externa tras las operaciones con agua del arroyo. Respecto a su tío Paco, al que Pacífico adoraba, se omite la parte en que cuenta cómo le descubre el hoyo de la Torca Palomera, lleno de muertos, apariciones y fuegos fatuos (1975: 74-77). Por último, cuando Pacífico está en la cárcel se sintetizan los momentos en que desarrolla el autor la relación de Pacífico con los presos y la historia de cada uno (1975: 195-215); en la versión, para agilizar la acción, se centra en los compañeros que participan en la fuga y en su líder don Santiago (1990: 61-69) para demostrar finalmente la inocencia de Pacífico respecto al asesinato del vigilante (1990: 66). 
194 Tropelías. Revista de Teoría de la Literatura y Literatura Comparada, 27 (2017) María Soledad Gómez Ruiz

\section{Conclusiones}

A la luz del concepto definido por Roland Barthes en "El teatro de Baudelaire" (1967: 49-53), es preciso reconocer que las tres novelas de Delibes poseen una teatralidad implícita que demuestra su éxito al acomodarlas al teatro por el propio autor. En primer término, el monólogo es por naturaleza más dramático que narrativo por la tensión emocional; de ello se deduce la teatralidad implícita de Cinco horas con Mario. El monólogo dramático intensifica la tensión que existe entre lo que dice la viuda, su forma de pensar y los conflictos con el marido y, por el contrario, el silencio del muerto y la incomunicación de la pareja expresada por Carmen en cada recuerdo que rememora con distintos estados de ánimo y sentimientos. Por otra parte, me parece muy útil aplicar la tipología de adaptaciones de la novela al cine de Sánchez Noriega (2000: 64) — basadas en la dialéctica entre fidelidad y creatividad - para las versiones teatrales de las novelas de Delibes. Por tanto, se deduce que Cinco horas con Mario es una adaptación como transposición de la novela y se mantiene el drama analítico de la relación de una pareja totalmente opuesta que también refleja el conflicto de una época: la guerra civil y los dos bandos, la posguerra y los años sesenta y setenta que representan la generación de Carmen y Mario, protagonista y antagonista.

En segundo término, La hoja roja plantea una trama progresiva perfectamente adaptable al teatro. Delibes elimina al narrador omnisciente y potencia el punto de vista de los personajes. Todo el discurso se acoge a la modalidad del diálogo. La trama es trasladada a la versión condensando los hechos y omitiendo algunos personajes y subtramas, como se ha dicho, que no desvirtúan la novela. Lo más acertado de la versión es el comienzo in media res con el discurso de jubilación de don Eloy. Desde ese momento la estructura dramática muestra en dos actos los dos conflictos, el clímax, el desenlace y la transformación de don Eloy y Desi. Las acotaciones sirven para aportar las indicaciones sobre el tiempo, el espacio y las acciones de los personajes. Se condensan los lugares de la acción en la versión y no cambian respecto a la novela los siete decorados principales. Se trata de una adaptación como transposición de la novela, en ella los personajes y pasajes omitidos sirven para condensar la acción dramática de ambos protagonistas y se respeta plenamente el espíritu de la novela.

Por último, la versión teatral de Las guerras de nuestros antepasados es fiel al hipotexto y respeta los hechos que conforman la trama de la novela dialogada de forma fidedigna. Digamos que para la versión teatral, Miguel Delibes y Ramón García sintetizan los fragmentos que dilatarían el tiempo de la representación y no añaden matices diferentes al desenlace de la historia, y, por otra parte, suprimen de la novela los temas y motivos que no son relevantes para el espectador. La conclusión del análisis comparativo de ambos textos sería que la versión acentúa la visión ideológica 
del perdedor. Se trata de una adaptación como ilustración de la novela aunque se incluye también la interpretación al potenciar el punto de vista dramático en el desenlace con la condena a garrote vil (1975: 296).

\section{Bibliografía}

BAJTÍN, Mijail (1982): “El problema de los géneros literarios”, en Estética de la creación verbal. México, Siglo XXI, pp. 248-293.

BAREI, Silvia (1991): De la escritura y sus fronteras. Córdoba, Alción.

BARTHES, Roland (1967): “El teatro de Baudelaire”, Ensayos críticos. Barcelona, Seix Barral, pp. 49-53.

DELIBES, Miguel (2010): La hoja roja. Madrid, Austral.

_ (1987): La hoja roja, versión teatral. Barcelona, Destino.

_ (1975): Las guerras de nuestros antepasados. Barcelona, Destino Libro [1993, 6. a ed.].

_ (1990): Las guerras de nuestros antepasados, versión teatral. Barcelona, Destino.

_ (2010): Cinco horas con Mario. Madrid, Austral.

— (1981): Cinco Horas con Mario, versión teatral, introd. de Gonzalo Sobejano. Madrid, Espasa Calpe.

GENETTE, Gérard (1989): Palimpsestos. La Literatura en segundo grado. Madrid, Taurus.

KRISTEVA, Julia (1997): "Bajtín, la palabra, el diálogo y la novela", Intertextualité. Francia en el origen de un término y el desarrollo de un concepto. Ed. Desiderio Navarro. La Habana, Casa de las Américas, pp. 1-24.

SÁNCHEZ NORIEGA, José Luis (2000): De la literatura al cine. Teoría y práctica de la adaptación. Barcelona, Paidós Ibérica. 